\title{
Type of Coronary Artery Plaque in Relation to Epicardial Fat Volume in Coronary Heart Disease Patients: A Cardiac Computed Tomography Scan Study
}

\author{
Iman Imaduddin Robandi, Ristaniah D. Soetikno, Dian K. Dewi \\ Department of Radioloy Faculty of Medicine Universitas Padjadjaran \\ Dr. Hasan Sadikin General Hospital Bandung, Indonesia
}

\begin{abstract}
Background: Coronary heart disease (CHD) is a disease that raises public health concerns due to its high morbidity and mortality rates. Anatomically, epicardial fat is located around the heart and coronary system, making it important in the development of coronary atherosclerosis. This study aimed to explore the relationship between epicardial fat volume (EFV) and the type of coronary artery plaque by using Cardiac Computed Tomoghraphy (CT)-Scan.

Methods: This was a cross-sectional observational analytic study on patients diagnosed with CHD aged $>20$ years who had undergone cardiac CT-Scan at the Department of Radiology, Dr. Hasan Sadikin General Hospital, Bandung, Indonesia between February and June 2019. Data collected from the CTScan were analyzed using the Chi-square test.

Results: From 54 CHD patients, consisting of an equal number of male and female patients, with a majority of above 60 years old (31.5\%), a correlation was identified between increased amount of EFV and mix and hard plaques in the right cirumflex artery (RCA) $(\mathrm{p}<0.026)$ and left circumflex $($ LCX) $(\mathrm{p}<0.038)$ On the left main(LM) and left anterior descending (LAD) arteries, no significant correlation was observed between EFV and the type of plaque ( $p>0.05)$.

Conclusions: There is a significant relationship between the EFV value, EFV category, and the type of coronary artery plaque in CHD patients in RCA and LCX arteries. However, this correlation is not observed in LM and LAD arteries.
\end{abstract}

Keywords: Artery plaque, cardiac CT-Scan, coronary heart disease, epicardial fat volume

\section{Introduction}

Coronary heart disease (CHD) is a disease caused by plaque that has accumulated in the lumen of the coronary arteries, leading to a limited supply of oxygen to the heart muscle. ${ }^{1-3}$ The CHD is one of the most common cardiovascular diseases, a disorder of the heart and blood vessels including stroke, rheumatic heart disease, and other conditions. ${ }^{4}$ According to world statistics, there are 9.4 million deaths each year caused by cardiovascular disease, and $45 \%$ of these deaths are caused by CHD. It is estimated that the number will increase to 23.6 million in 2030.,5 In 2013, the highest prevalence for cardiovascular disease in Indonesia is CHD. The incidence of CHD is mainly found in the age between 65-
74 years $(3.6 \%)$ followed by the age group of 75 years and above (3.2\%), the age group of 55-64 years $(2.1 \%)$, and the age group 35-44 years old $(1.3 \%){ }^{6}$ Dr. Hasan Sadikin General Hospital Bandung has handled the cases of CHD in 2017 as many as 764 outpatients and 3836 inpatients, with the incidence of male patients more than women, a ratio of $4: 1 .^{7}$

The development of atherosclerosis is started with the formation of foam cells that are induced by chronic hyperlipidemia, namely excessive fat intake in a long time. ${ }^{8}$ Epicardial fat can affect the formation of coronary atherosclerosis due to the absence of a fibro fascia layer that is able to inhibit the diffusion of free fatty acids and adipokines from epicardial fat to the walls of the blood vessels and surrounding heart muscle. ${ }^{9}$ The accumulation

Correspondence: Iman Imaduddin Robandii, Department of Radiology Faculty of Medicine Universitas Padjadjaran/Dr. Hasan Sadikin General Hospital, Jalan Pasteur 38, Bandung, Indonesia, E-mail: imaduddinr142@gmail.com 
of epicardial fat increases the secretion of local inflammatory mediator that triggers atherosclerotic processes and other systemic effects. ${ }^{9,10}$ Previous studies have shown that increased epicardial fat volume (EFV) might progress into coronary atherosclerosis in the near to medium term with an average of $2.7 /$ year $)^{10}$ The thickening of epicardial adipose tissue should be considered as a more accurate risk factor in cardiovascular disease. ${ }^{11}$ Hence, it is a potential therapeutic target, as well as an examination target that shows an association between epicardial fat and coronary heart disease by using a cardiac computed tomography (CT)scan. CT-scan is more accurate in measuring the accumulation of adipose tissue or epicardial fat due to higher spatial resolution. ${ }^{11}$

Measurement of EFV can be performed using several imaging modalities such as echocardiography, cardiac CT-scan with Multi Sliced Computed Tomography (MSCT), and Magnetic Resonance Imaging (MRI). The EFV measurement using a cardiac CT-scan with or without contrast is conducted manually by tracing the epicardial layer in each piece from the appendix atrium to the heart apex. The thickness of epicardial fat is identified by Hounsfield Units (HU) which is set at -250 to -30 , then the computer measures EFV automatically. ${ }^{12,13}$ Another study has shown the normal EFV value $<125 \mathrm{ml}$. Value $>125 \mathrm{ml}$ is considered not normal, however, EFV $>100$ $\mathrm{ml}$ is able to estimate CHD. ${ }^{12}$

Epicardial fat has a role in atherosclerosis, an increase in epicardial fat volume has a relationship with the type of plaque without calcification and plaque with a mixture of calcifications that cause stenosis in the coronary artery lumen. ${ }^{13}$ The influence of epicardial fat volume on the degree of severe coronary artery stenosis is mainly due to soft plaque and mix plaque-type atherosclerosis. ${ }^{14}$

Epicardial fat tissue contributes to the pathogenesis of coronary atherosclerosis. Atherosclerotic plaques are classified into calcified, non-calcified, and mixed lesions. The attenuation assessment of $\mathrm{HU} \geq 130$ is considered the type of calcification. A cardiac CT-scan analysis has shown that calcified plaque if at least $0.5 \mathrm{~mm}^{2}$ in the identified area diameter has a density $\geq 130 \mathrm{HU} \cdot{ }^{15}$ Furthermore, uncalcified plaques are divided into 2 based on Hounsfield unit (HU) values, which are low plaque (HU 0-49) that is considered to be lipid-rich plaques, and medium (HU 50-129) is considered fibrous-rich plaques. ${ }^{15}$ In plaques that show calcification $\leq 50 \%$ of the plaque area is classified as a mixture. ${ }^{12}$ Since research on the relationship of coronary artery plaque

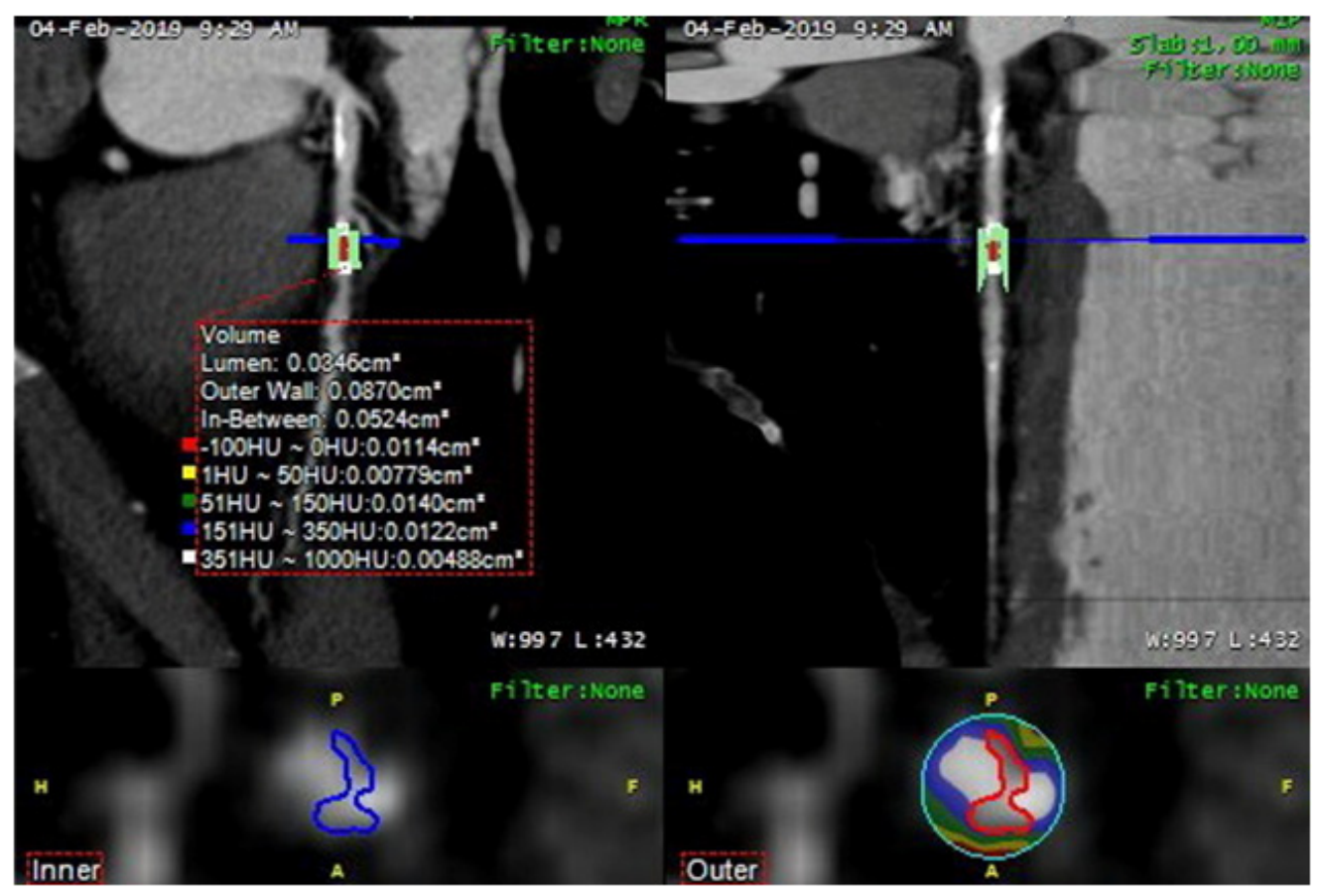

Figure 1 Assessment of The Type of Coronary Artery Plaque 


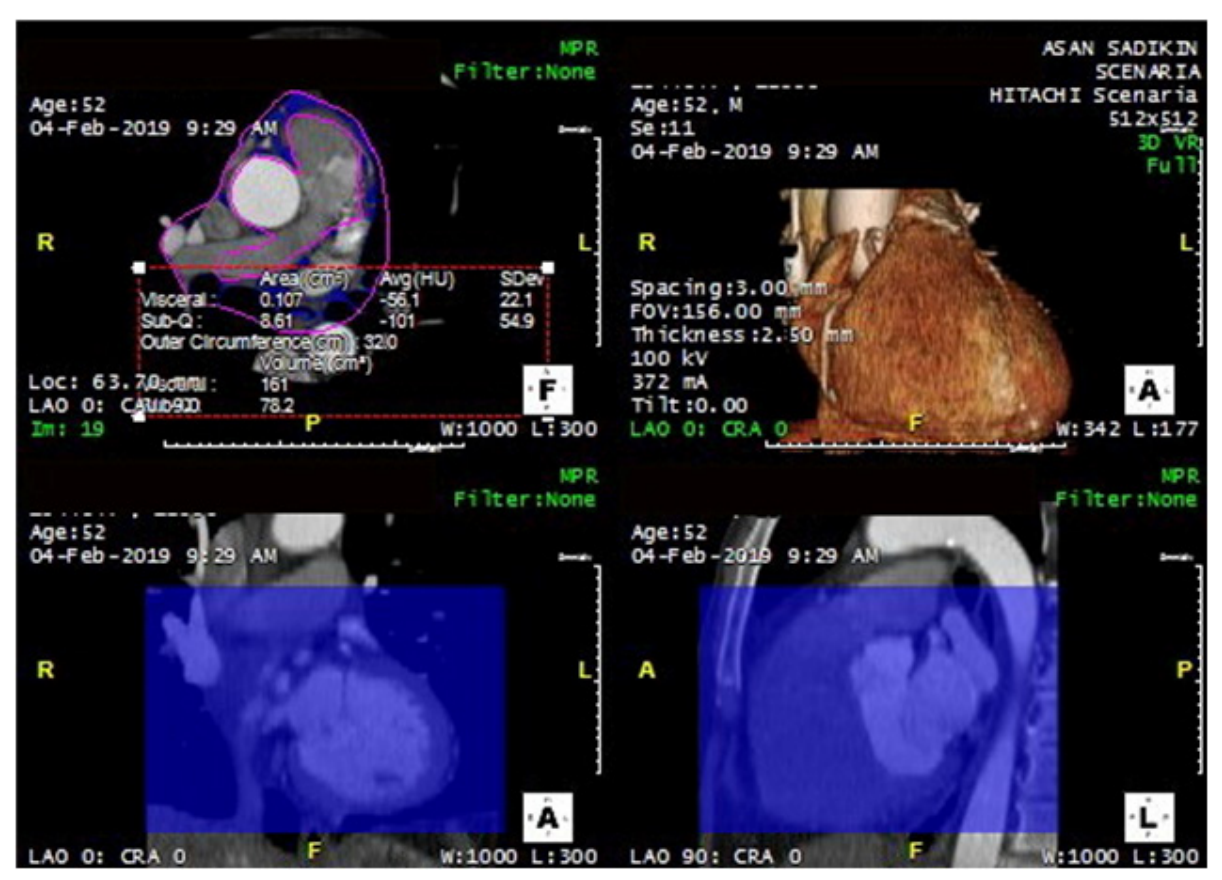

Figure 2 Assessment of Epicardial Fat Volume

types with epicardial fat volume in patients with coronary heart disease using a CT scan of the heart has never been done in the Dr. Hasan SadikinGeneral Hospital Bandung, this study aimed to find the relationship of coronary artery plaque types with epicardial fat volume in patients with coronary heart disease using a CT scan of the heart.

\section{Methods}

This study was an observational analytic study with a cross-sectional design, conducted in patients with CHD. The CHD patients aged $>20$ years old, who underwent cardiac CT Scan at Dr. Hasan Sadikin General Hospital Bandung from February to June 2019 were recruited. This study measured epicardial fat volume (EFV) and the type of coronary artery plaque based on calcification formed. This study was approved by the Ethical Committee of Dr. Hasan Sadikin General Hospital Bandung with the number LB.02.01/X.6.5/111/2019.

In brief, cardiac 128-slice CT scans (The Scenaria SE, Hitachi Healthcare) was used, consisting of Digital Imaging and Communication in Medicine (DICOM) data. Aquarius iNtuition client ver.4.4.12.196.3577 post-processing workstation, Terarecon software, Terarecon CT-cardiac workflow Software Terarecon-Aquarius iNtuition client ver. 4.4.12.196.3577, Terarecon 3D Fat
Analysis. Trace data on the results of the CTscan of the heart i.e. the type of plaque on the coronary arteries (Figure 1) and the FEV (Figure 2).

The assessment of coronary artery stenosis by reconstructing DICOM data using Terarecon software, CT-Cardiac Analysis Workflow that made a reconstruction of volume rendering technique (VRT), multi planar reformation (MPR), curved planar reformation (CPR), then the amount of stenosis in each branch of the coronary arteries i.e. right circumflex artery (RCA), left circumflex (LCX) artery, left ain (LM) artery left anterior descending (LAD) artery was assessed.

Coronary artery stenosis was caused by atherosclerotic plaque lesions in the form of calcified, non-calcified, or mixed plaque. Quantitative measurement of plaque types was measured using plaque analysis methods by assessing the hounsfield units (HU). The coronary CT-scan images were analyzed using an image archiving and communication system. If an abnormal segment was identified, the coronary artery was evaluated using the Aquarius Workstation (TeraRecon, San Mateo, $\mathrm{CA}$ ) and the non-calcified plaque volume was measured. Categories based on CT (HU) value: low (HU 0-49; considered plaque rich in fat) and moderate attenuation composition (HU 50-129; considered as fibrous plaque). The plaque was color-coded and the volume of 
Table 1 Characteristics of Patients with Coronary Heart Disease from Dr. Hasan Sadikin General Hospital

\begin{tabular}{|c|c|c|}
\hline Characteristics & Total (n) & Percentage (\%) \\
\hline \multicolumn{3}{|l|}{ Gender } \\
\hline Male & 27 & 50.0 \\
\hline Female & 27 & 50.0 \\
\hline \multicolumn{3}{|l|}{ Age (Years) } \\
\hline$\leq 30$ & 4 & 7.4 \\
\hline $31-40$ & 6 & 11.1 \\
\hline $41-50$ & 12 & 22.2 \\
\hline $51-60$ & 15 & 27.8 \\
\hline$>60$ & 17 & 31.5 \\
\hline \multicolumn{3}{|l|}{ Epicardial Fat Volume } \\
\hline Normal $<125 \mathrm{~mL}$ & 17 & 31.5 \\
\hline Abnormal >125 mL & 37 & 68.5 \\
\hline \multicolumn{3}{|l|}{ Ejection Fraction } \\
\hline Averange $\pm S D$ & \multicolumn{2}{|c|}{$49.33 \pm 18.81$} \\
\hline Median (Min-Max) & \multicolumn{2}{|c|}{$52.58(13.92-88.49)$} \\
\hline \multicolumn{3}{|l|}{ Calcium Score } \\
\hline Averange $\pm S D$ & \multicolumn{2}{|c|}{$398.72 \pm 776.30$} \\
\hline Median (Min-Max) & \multicolumn{2}{|c|}{$65.10(0.0-4778)$} \\
\hline
\end{tabular}

each component was measured. The colorcoded area was manually adjusted, including the thickness of the blood vessel wall, and the surrounding tissue is eliminated. A 2 Curved multiplanar reconstructing baselines and follow-up CT were displayed in parallel and then identical segments were compared side by side using the Aquarius workstation. 15

As for the EFV measurement procedure, Terarecon-Aquarius iNtuition client software ver. 4.4.12.196.3577, Terarecon 3D Fat Analysis was used. With the semi-automatic method on axial pieces with a thickness of 1-3 $\mathrm{mm}$, it was done manually by tracing the epicardial layer in each cut from the appendix to the atrium of the heart. Epicardial adipose tissue was identified by Hounsfield units (HU) which were set at -250 to -30 , then EFV was then automatically measured by the computer. The epicardial fat volume (EFV) data was then categorized as normal and abnormal. Epicardial fat was identified as a hypodense lesion that surrounded the myocardium and was bounded by the pericardium

The EFV data normality test was conducted with the Saphiro Wilk test $(n=54)$ and data was normal distributed if the value of $p>$ 0.05 . The bivariate analysis aimed to examine the relationship of EFV with the degree of coronary artery stenosis, using the ANOVA test if the EFV data were normally distributed, or the KruskallWallist Test if the EFV data were not normally distributed. Data analysis was performed using the Statistical Product and Service Solution (SPSS) program for Windows version 18.0.

\section{Results}

Of 54 CHD patients, that were equally distributed in gender, the majority was aged above 60 years (31.5\%). The majority had a volume of epicardial fat detected $>125 \mathrm{ml}$ which was categorized as abnormal. The average value of fraction ejection was 49.33 range 13.92-88.49). The average of calcium score was 398.72 (range 0-4778).

There was a significant relationship in the value and category of EFV with the type of coronary artery plaque in CHD patients. It was not all plaque collection sites had the same results. In RCA and LCX, plaque type 
Table 2 Correlation of Plaque Types with Epicardial Fat Volume

\begin{tabular}{|c|c|c|c|c|c|}
\hline & \multirow{2}{*}{ Plaque/Burdens } & \multicolumn{2}{|c|}{ Epicardial Fat Volume } & \multirow{2}{*}{ Total } & \multirow{2}{*}{ p-value } \\
\hline & & Normal & Abnormal & & \\
\hline \multirow{3}{*}{ RCA } & Soft & $3(37.5 \%)$ & $5(62.5 \%)$ & $8(100 \%)$ & $0.026^{*}$ \\
\hline & Hard & $5(17.2 \%)$ & $24(82.8 \%$ & $29(100 \%)$ & \\
\hline & Mix & $9(56.3 \%)$ & $7(43.8 \%)$ & $16(100 \%)$ & \\
\hline \multirow{3}{*}{ LM } & Soft & $2(25.0 \%)$ & $6(75,0 \%)$ & $8(100 \%)$ & 0.802 \\
\hline & Hard & $2(14.3 \%)$ & $12(85.7 \%)$ & $14(100 \%)$ & \\
\hline & Mix & $2(22.2 \%)$ & $7(77.7 \%)$ & $9(100 \%)$ & \\
\hline \multirow{3}{*}{ LAD } & Soft & $1(100.0 \%)$ & $0(0.0 \%)$ & $1(100 \%)$ & 0.183 \\
\hline & Hard & $6(22.2 \%)$ & $21(77.8 \%)$ & $27(100 \%)$ & \\
\hline & Mix & $8(34.8 \%)$ & $15(65.2 \%)$ & $23(100 \%)$ & \\
\hline \multirow{3}{*}{ LCX } & Soft & $6(60.0 \%)$ & $4(40.0 \%)$ & $10(100 \%)$ & $0.038^{*}$ \\
\hline & Hard & $3(15.0 \%)$ & $17(85.0 \%)$ & $20(100 \%)$ & \\
\hline & Mix & $6(28.6 \%)$ & 15 (71.4\%) & $21(100 \%)$ & \\
\hline
\end{tabular}

Note: RCA= right circumflex artery, LM= left main, LAD= left anterior descending, LCX= left circumflex. * was statistically significant $\mathrm{p}<0.05$

and epicardial fat volume had a significant correlation with $\mathrm{p}=0.026$ and $\mathrm{p}=0.038$, respectively. In contrast, in the LM and LAD, no significant different between the type of plaque and epicardial fat volume (Table 2).

\section{Discussions}

This study shows the characteristics of patients with coronary heart disease (CHD) of whom the relationship has been analyzed between the epicardial fat volume (EFV), and the type of plaque in the coronary arteries. Interestingly, measurement of epicardial fat volume carried out at the workstation as described by Gorteret al. in Bertaso et al. did not reveal the assessment of the visceral layer of the pericardium. ${ }^{13}$ It was carried out manually from the center of the left atrium to the top of the left ventricle, and all extrapericardial tissue was eliminated. The images then segmented using attenuation thresholds that vary between $-250 \mathrm{HU}$ and $-30 \mathrm{HU}$ so that they depict the epicardial fat portion in each slice. This did not include myocardium, coronary arteries, coronary calcium, aorta, and blood clusters. The epicardial fat area at each level was added across the slices and multiplied by the thickness of the slices and the number of slices to determine the total epicardial fat volume (Figure 2). This method is also used to measure epicardial fat volume reported by Alexopoulos et al. ${ }^{13}$

Age distribution ranges from 30 years to 80 years. This is adjusted to the inclusion criteria taken. The age characteristics of the subjects of this study are in accordance with 2015 Heart Disease and Stroke Heart Disease statistical data which states the prevalence of CHD in the United States starting from age $>20$ years and the coronary artery atherosclerosis process begins to emerge in the second decade of life.

The age distribution and the amount of epicardial fat volume have a bearing on the potential for coronary atherosclerosis, so in this case, it is directly proportional to the increase in the increase in the calcium score. There is conformity with the types of soft plaque, mix plaque, and hard plaque. This study found the results of coronary compliance in RCA and LCX patients who have epicardial volume values of more than $125 \mathrm{ml}$ have a correlation with the type of mix plaque and hard plaque.

The majority of CHD patients in our study was aged above 60 years with a percentage of $31.5 \%$, however, there was also an age over 30 years have significant value (Table1). The volume of epicardial fat detected is predominantly above $125 \mathrm{ml}$ which is included in the abnormal category $(n=37)$ that directly proportional to the average age above 60 years affected by CHD. The average of fraction 
ejection is 49.33 (range 13.92-88.49) and the average of calcium score is 398.72 with a wide range (0-4778).

The average volume of epicardial fat found in population-based studies ranged from $68 \pm 34 \mathrm{ml}$ to $124 \pm 50 \mathrm{ml}$. In a study including patients from the Framingham group, the average volume of epicardial fat was $110 \pm 41 \mathrm{ml}$ in women and $137 \pm 53 \mathrm{ml}$ in men. ${ }^{16}$ Epicardial fat is a deposit of visceral fat which partly shares its metabolic and systemic inflammatory effects so that it has an effect on the wall coronary arteries. Epicardial fat is consistently associated with metabolic syndrome and coronary heart disease. According to current knowledge, EF thickness $>5 \mathrm{~mm}$, or volume $>125 \mathrm{ml}$ or $68 \mathrm{ml} / \mathrm{m}^{2}$ are considered abnormal. ${ }^{16}$

In accordance with data from the Ministry of Health Republic of Indonesia in 2013, Bertaso et al. ${ }^{16}$ has suggested that the normal EFV value is $<125 \mathrm{ml}$ and the not normal $>125 \mathrm{ml}$. However, other study argued that epicardial fat has a role in atherosclerosis, an increase in epicardial fat volume has a relationship with the type of plaque without calcification and plaque with a mixture of calcifications that cause stenosis in the coronary artery lumen. ${ }^{13}$ The effect of epicardial fat volume on the degree of severe coronary artery stenosis mainly due to soft plaque and mix-hard plaque type or atherosclerosis. ${ }^{14}$

The limitation of this study is that this study did not include risk factors for CHD among patients. Furthermore, the evaluation of EFV and the degree of coronary artery stenosis is highly dependent on the operator's ability to reconstruct DICOM data from cardiac CT scans

To conclude, there is a significant relationship between the EFV value, EFV category, and the type of coronary artery plaque in CHD patients in RCA and LCX arteries. However, this correlation is not observed in LM and LAD arteries.

Further research needs to be done with a greater number of subjects and vary both female and male patients, including the coverage of all adults, including other risk factors for CHD in patients undergoing cardiac CT-scan examination.

\section{References}

1. American Heart Association. Coronary artery disease-coronary heart disease. article. 2015. [cited 2019 January 26] Available from: https://www.heart.org/ en/health-topics/consumer-healthcare/ what-is-cardiovascular-disease/coronaryartery-disease

2. National Heart, Lung, and Blood Institute (NHLBI). Coronary heart disease. 2017. [cited 2019 January 26]. Available from: https://www. nhlbi.nih.gov/health-topics/coronaryheart-disease\#: : text=Coronary $\% 20$ microvascular $\% 20$ disease $\% 20$ affects $\% 20$ the,Heart\%20Works\%20to\%20learn $\% 20$ more.

3. Kotseva K, Wood D, De Bacquer D, De Backer G, Rydén L, Jennings C, et al.. EUROASPIRE IV: A European Society of Cardiology survey on the lifestyle, risk factor and therapeutic management of coronary patients from 24 European countries. Eur J Prev Cardiol. 2016;23(6):636-48.

4. European Society of Gynecology (ESG), Association for European Paediatric Cardiology (AEPC), German Society for Gender Medicine (DGesGM), RegitzZagrosek V, Lundqvist CL, Borghi C, et al. ESC Guidelines on the management of cardiovascular diseases during pregnancy: the Task Force on the Management of Cardiovascular Diseases during Pregnancy of the European Society of Cardiology (ESC). Eur Heart J. 2011;32(24):3147-97.

5. Wong ND. Epidemiological studies of CHD and the evolution of preventive cardiology. Nat Rev Cardiol. 2014;11(5):276-89.

6. Biro Komunikasi dan Pelayanan Masyarakat Kementerian Kesehatan RI. Penyakit jantung penyebab kematian tertinggi, Kemenkes ingatkan CERDIK. 2017. [cited 2019 January 30] Available from:.http://sehatn egeriku.kemkes. go.id/baca/umum/20170801/2521890/ penyakit-jantung-penyebab-kematiantertinggi-kemenkes-ingatkan-cerdik$2 / \#: \sim$ :text=Penyakit $\% 20$ Jantung $\% 20$ $\mathrm{Pen}$ y e b a b \% $20 \mathrm{Ke} \mathrm{m}$ at i a $\% 20$ Tertinggi $\% 2$ C $\% 20$ Kemenkes $\% 20$ Ingatkan $\% 20$ CERDIK,-0\&text=Survei $\% 20$ Sample\%20Regristration $\% 20$ System $\% 20$ (SRS,yakni\%20sebesar\%2012\%2C9\%25.

7. Rumah Sakit Dr. Hasan Sadikin. Rangking penyakit di instalasi Rawat Inap dan Rawat Jalan Periode Januari-Desember 2017. Bandung: Rumah Sakit Dr. Hasan Sadikin;2017.

8. Chatzikonstantinou A, Ebert AD, Schoenberg SO, Hennerici MG, Henzler T. Atherosclerosis in intracranial, extracranial, and coronary arteries with aortic plaques in patients with ischemic stroke of undetermined etiology. Int J 
Neurosci. 2015;125(9):663-70.

9. Sacks HS, Fain JN, Holman B, Cheema P, Chary A, Parks F, et al. Uncoupling protein-1 and related messenger ribonucleic acids in human epicardial and other adipose tissues: epicardial fat functioning as brown fat. J Clin Endocrinol Metab. 2009;94(9):3611-5.

10. Yerramasu A, Dey D, Venuraju S, Anand DV, Atwal S, Corder R, et al. Increased volume of epicardial fat is an independent risk factor for accelerated progression of sub-clinical coronary atherosclerosis. Atherosclerosis. 2012;220(1):223-30.

11. Demircelik MB, Yilmaz OC, Gurel OM, Selcoki Y, Atar IA, Bozkurt A, et al. Epicardial adipose tissue and pericoronary fat thickness measured with 64-multidetector computed tomography: potential predictors of the severity of coronary artery disease. Clinics (Sao Paulo). 2014;69(6):388-92.

12. Aslanabadi N, Salehi R, Javadrashid A, Tarzamni M, Khodadad B, Enamzadeh E, et al. Epicardial and pericardial fat volume correlate with the severity of coronary artery stenosis. J Cardiovasc Thorac Res. 2014;6(4):235-9.

13. Alexopoulos N, McLean DS, Janik M, Arepalli CD, Stillman AE, Raggi P. Epicardial adipose tissue and coronary artery plaque characteristics. Atherosclerosis. 2010;210(1):150-4.

14. Rajani R, Shmilovich $H$, Nakazato $R$, Nakanishi R, Otaki Y, Cheng VY, et al. Relationship of epicardial fat volume to coronary plaque, severe coronary stenosis, and high-risk coronary plaque features assessed by coronary CT angiography. J Cardiovasc Comput Tomogr. 2013;7(2):125-32.

15. You S, Sun JS, Park SY, Baek Y, Kang DK. Relationship between indexed epicardial fat volume and coronary plaque volume assessed by cardiac multidetector CT. Medicine (Baltimore). 2016;95(27):e4164.

16. Bertaso AG, Bertol D, Duncan BB, Foppa M. Epicardial fat: definition, measurements and systematic review of main outcomes. Arq Bras Cardiol. 2013;101(1):e18-28. 